HRTEM Study of Oxide Nanoparticles in K3-ODS Ferritic Steel Developed for Radiation Tolerance

L. Hsiung, M. Fluss, S. Tumey, J. Kuntz, B. El-Dasher, M. Wall, W. Choi, A. Kimura, F. Willaime, Y. Serruys

November 5, 2009

Journal of Nuclear Materials 
This document was prepared as an account of work sponsored by an agency of the United States government. Neither the United States government nor Lawrence Livermore National Security, LLC, nor any of their employees makes any warranty, expressed or implied, or assumes any legal liability or responsibility for the accuracy, completeness, or usefulness of any information, apparatus, product, or process disclosed, or represents that its use would not infringe privately owned rights. Reference herein to any specific commercial product, process, or service by trade name, trademark, manufacturer, or otherwise does not necessarily constitute or imply its endorsement, recommendation, or favoring by the United States government or Lawrence Livermore National Security, LLC. The views and opinions of authors expressed herein do not necessarily state or reflect those of the United States government or Lawrence Livermore National Security, LLC, and shall not be used for advertising or product endorsement purposes. 


\title{
HRTEM Study of Oxide Nanoparticles in K3-ODS Ferritic Steel Developed for Radiation Tolerance
}

\author{
L. Hsiung, ${ }^{\mathrm{a},}$, M. Fluss ${ }^{\mathrm{a}}$, S. Tumey ${ }^{\mathrm{a}}$, J. Kuntz ${ }^{\mathrm{a}}$, B. El-Dasher ${ }^{\mathrm{a}}$, M. Wall ${ }^{\mathrm{a}}$, B. Choi ${ }^{\mathrm{a}}$, A. Kimura ${ }^{\mathrm{b}}$, \\ F. Willaime ${ }^{c}$, Y. Serruys ${ }^{c}$ \\ ${ }^{a}$ Lawrence Livermore National Laboratory \\ Physical and Life Sciences Directorate \\ Livermore, CA94551, U.S.A. \\ ${ }^{\mathrm{b}}$ Institute of Advanced Energy \\ Kyoto University, Gokasho, Uji \\ Kyoto 611-0011, Japan \\ 'Service de Recherches de Métallurgie Physique (CEA) \\ Gif-sur-Yvette 91191, France
}

\begin{abstract}
Crystal and interfacial structures of oxide nanoparticles and radiation damage in 16Cr-4.5Al-0.3Ti$2 \mathrm{~W}-0.37 \mathrm{Y}_{2} \mathrm{O}_{3}$ ODS ferritic steel have been examined using high-resolution transmission electron microscopy (HRTEM) techniques. Oxide nanoparticles with a complex-oxide core and an amorphous shell were frequently observed. The crystal structure of complex-oxide core is identified to be mainly monoclinic $\mathrm{Y}_{4} \mathrm{Al}_{2} \mathrm{O}_{9}$ (YAM) oxide compound. Orientation relationships between the oxide and the matrix are found to be dependent on the particle size. Large particles $(>20 \mathrm{~nm})$ tend to be incoherent and have a spherical shape, whereas small particles $(<10 \mathrm{~nm})$ tend to be coherent or semi-coherent and have a faceted interface. The observations of partially amorphous nanoparticles and multiple crystalline domains formed within a nanoparticle lead us to propose a three-stage mechanism to rationalize the formation of oxide nanoparticles containing core/shell structures in as-fabricated ODS steels. Effects of nanoparticle size and density on cavity formation induced by $\left(\mathrm{Fe}^{8+}+\mathrm{He}^{+}\right)$dual-beam irradiation are briefly addressed.
\end{abstract}

\section{Introduction}

Development of high-performance structural materials for first wall and breeding-blanket components, which will be exposed to high fluxes of high energy $(14 \mathrm{MeV})$ neutrons from the deuterium-tritium fusion, is one of the major challenges in materializing future fusion reactors. The choice of structural materials for the first wall and blanket to a large degree dictates the design of the fusion reactor systems. In particular, the allowable power plant operating temperature, the choice of coolant, and the power conversion system are critically dependent on the structural materials. The selection of suitable structural materials is based on conventional properties (such as thermophysical, mechanical, and corrosion and compatibility), low neutron-induced radioactivity, and resistance to radiation-induced damage phenomena like material hardening/embrittlement and/or dimensional instability caused by void- and helium-driven swelling [1, 2]. Reduced activation ferritic/martensitic (F/M) steels, which possess modified compositions of commercial ferritic/martensitic steels by exchanging $\mathrm{Mo}, \mathrm{Nb}$, and $\mathrm{Ni}$ with $\mathrm{W}, \mathrm{V}$, and Ta for low long-term radioactivity, have been selected as

\footnotetext{
* Corresponding author. Tel.: +1-925 424 3125; fax: +1-925 4243815

E-mail address: hsiung1@|lnl.gov (L. Hsiung).
} 
one of the primary candidate structural materials for fusion reactor applications because of their high thermal conductivity, good resistance to radiation-induced swelling and helium-induced embrittlement in experimental tests. The service temperature capability of reduced activation F/M steels is, however, limited to around $600{ }^{\circ} \mathrm{C}$ because of their inferior tensile and creep strength at high temperatures. Oxide dispersion strengthened (ODS) F/M and ferritic steels, which produced by mechanical alloying the elemental or pre-alloyed powders complemented with yttria $\left(\mathrm{Y}_{2} \mathrm{O}_{3}\right)$ powder consolidated by hot extrusion or hot isostatic pressing, are advanced structural materials with a potential to be used at elevated temperatures due to the dispersion of thermally stable oxide nanoparticles into the F/M matrix. The use of ODS steels can improve creep strength and oxidation/corrosion resistance at high temperatures, and consequently increase the operating temperature of first wall and blanket structures in future fusion reactors by at least $100{ }^{\circ} \mathrm{C}$ to approximately $700{ }^{\circ} \mathrm{C}$ or higher [3].

Significant progress has been made during the last two decades to understand the processingmicrostructure-property relationships of ODS F/M steels, which led to the development of materials with exceptional high-temperature microstructural stability and creep strength coupled with effective trapping of transmutation gases. However, several key issues remain unsolved that include incomplete understanding of the effect of irradiation on low-temperature fracture properties, the role of fusionrelevant helium and hydrogen transmutation gases on the deformation and fracture of irradiated materials, and mechanisms of swelling suppression in ODS steels [4, 5]. Since no prototype fusion reactors currently exist, it is difficult to directly evaluate the high-energy neutron damage environment expected to prevail in the first wall of a fusion reactor. One technique commonly used to study the evolution of defect structures and the nucleation and growth of voids utilizes transmission electron microscopy (TEM) examinations of specimens simultaneously bombarded by heavy ions and helium and/or deuterium ions through so called "dual-beam" and "triple-beam" simulation experiments [6, 7]. The heavy ions create atomic displacements while the gas ions simulate the effects of transmutation gases, helium (10 appm/dpa) and hydrogen (40 appm/dpa). In preparation for the "dual-beam” and "triple-beam" experiments, we have conducted HRTEM characterization of an as-fabricated 16Cr-4Al0.3Ti-2W (K3) ODS steel and an irradiated K3-ODS steel obtained from our first (Fe + He) dual-beam experiment. Emphasis was placed on investigating the crystal and interfacial structures of oxide nanoparticles and those features that are important to the suppression of cavitational swelling due to the presence of nanoparticles.

\section{Experimental}

The material used for this investigation was a high-chromium aluminum-containing (16Cr-4.5Al) ODS ferritic steel, designated as K3-ODS steel [7]. A full description of the fabrication procedure for the ODS steels can be found elsewhere [8,9]. Briefly, the pre-alloyed powder was first mechanically alloyed with $\mathrm{Y}_{2} \mathrm{O}_{3}$ powder in an argon gas atmosphere at room temperature using an attrition type ball mill. The powder was then sealed in a stainless-steel can and degassed at $400{ }^{\circ} \mathrm{C}$ in $0.1 \mathrm{~Pa}$ pressure. The canned powders were subsequently consolidated by a hot extrusion technique at $1150{ }^{\circ} \mathrm{C}$. After the extrusion, the consolidated ODS steel was thermally treated at $1050^{\circ} \mathrm{C}$ for 1 hour. One ODS steel sample was also annealed at $900{ }^{\circ} \mathrm{C}$ for 168 hours (one week) for a thermal-stability study. The chemical composition (in wt.\%) of the consolidated material is C: 0.08 , Si: 0.033 , Cr: 16 , W: 1.82 , Al: 4.59, Ti: $0.28, \mathrm{Y}_{2} \mathrm{O}_{3}: 0.368$, and Fe: balance [7]. Thin foils of the as-fabricated ODS steel for TEM examination were prepared by a standard procedure that includes slicing, grinding, and polishing the recovered fragments with the foils surface approximately perpendicular to the loading axis. Final thinning of the foils was performed using a standard twin-jet electropolishing technique in an electrolyte (90 vol.\% acetic acid, 10 vol.\% perchloric acid) at $30 \mathrm{~V}$ and room temperature. Dual-beam irradiation 
using 24.18 $\mathrm{MeV} \mathrm{Fe}^{8+}$ ions for displacement damage and energy-degraded $1.7 \mathrm{MeV} \mathrm{He}^{+}$ions for helium injection was conducted using JANNUS facility at Saclay, France [10,11]. The irradiation temperature was controlled at $425 \pm 5{ }^{\circ} \mathrm{C}$ by monitoring the temperature of the specimen surface using infrared thermography during irradiation. The penetration depth of the $\mathrm{Fe}^{8+}$ ions was $\sim 3.2 \mu \mathrm{m}$ beneath the specimen surface and the implantation depth of helium was over a region extending from about 1.5 to $2.8 \mu \mathrm{m}$ from the specimen surface according to the calculation using TRIM code. The nominal conditions for ion irradiation are dose rate: 1 x 10 $10^{-3} \mathrm{dpa} / \mathrm{s}$, dose: $65 \mathrm{dpa}$, He/dpa: $100 \mathrm{appm} / \mathrm{dpa}$. A cross-section TEM foil (10 $\mu \mathrm{m}$ x $6 \mu \mathrm{m}$ x $<0.1 \mu \mathrm{m})$ of the irradiated ODS steel was prepared using a focused ion-beam (FIB) method. The foil was lifted out using a micro pick-up system and mounted onto a copper grid. TEM characterization was performed using a Phillips CM300 field-emission transmission electron microscope (accelerating voltage of $300 \mathrm{kV}$ ). A software package CaRIne Crystallography 3.1 was used to simulate electron diffraction patterns in order to identify the crystal structure of ODS nanoparticles.

\section{Results and discussion}

\subsection{Crystal and interfacial structures of nanoparticles}

A typical microstructure of K3 steel is shown in Figs. 1a-1b. Here elongated grains (Fig. 1a) and dense oxide nanoparticles (Fig. 1b), mainly $\mathrm{Y}_{4} \mathrm{Al}_{2} \mathrm{O}_{9}$ (YAM) complex oxide, were observed in K3-ODS steel. The sizes of nanoparticle in K3-ODS (Fig. 1b) are typically ranging from $2 \mathrm{~nm}$ to $20 \mathrm{~nm}$, the mean particle size is $\sim 6 \mathrm{~nm}$, and the particle density is on the order of $\sim 1 \times 10^{22} \mathrm{~m}^{-3} \cdot \mathrm{Y}_{4} \mathrm{Al}_{2} \mathrm{O}_{9}$ has a monoclinic structure and space group: $\mathrm{P} 2{ }_{1} / \mathrm{c}$ with $\mathrm{a}=0.7375 \mathrm{~nm}, \mathrm{~b}=1.0507 \mathrm{~nm}, \mathrm{c}=1.1113 \mathrm{~nm}$, and $\beta=$ $108.58^{\circ}[12,13]$. The formation of $\mathrm{Y}_{4} \mathrm{Al}_{2} \mathrm{O}_{9}$ oxide particles was identified and confirmed by matching numerous observed and simulated diffraction patterns of different zone axes, an example is shown in Figs. 1c for the $[0 \overline{1} 1]_{\mathrm{YAM}^{-}}$zone patterns. Their formation reveals the occurrence of an internal oxidation reaction: $2 \mathrm{Y}_{2} \mathrm{O}_{3}+\mathrm{Al}_{2} \mathrm{O}_{3} \rightarrow \mathrm{Y}_{4} \mathrm{Al}_{2} \mathrm{O}_{9}$ during consolidation that is governed by the affinity of oxygen to different solute atoms. This result is in agreement with a conclusion made by Kasada et al. [14]: Y-Ti complex oxides were not present, but instead Y-Al complex oxides were formed when ODS steels contain both $\mathrm{Al}$ and $\mathrm{Ti}$.

By comparing the $\mathrm{Y}_{4} \mathrm{Al}_{2} \mathrm{O}_{9}$ nanoparticles formed in the ODS steel with the starting $\mathrm{Y}_{2} \mathrm{O}_{3}$ (space group: $\mathrm{Ia}_{3}$, a cubic structure with $\mathrm{a}_{0}=1.06 \mathrm{~nm}$ [14], particle size: $15-30 \mathrm{~nm}$ [15]) particles used to fabricate the ODS steel, one could realize that the formation of oxide nanoparticles in ODS steels does not take place solely through a fragmentation mechanism. Complex mechanisms involving fragmentation, dissolution of $\mathrm{Y}_{2} \mathrm{O}_{3}$ particles, and precipitation of complex-oxide nanoparticles were previously proposed by Okuda and Fujiwara [16], Kimura et al. [17] and Sakasegawa et al. [18] based on the results generated from x-ray diffraction and conventional TEM studies. However, recent studies conducted by Marquis [19] using a 3-D atom probe method and Klimiankou et al. [20] using EDX and EELS methods have revealed the existence of a complex-oxide core structure associated with a soluteenriched shell structure in nanoparticles. The existence of core/shell structures in nanoparticles however challenges the accountability of previously proposed dissolution/precipitation mechanisms. HRTEM study of nanoparticles was thus carried out in order to examine the interfacial structure of nanoparticles. Important results and discussions are displayed below in order to rationalize the formation of core/shell structures in oxide nanoparticles. 
HRTEM images of a large $(>20 \mathrm{~nm})$ and two small $(<10 \mathrm{~nm})$ nanoparticles are shown in Figs. 2a, $2 \mathrm{~b}$ and 2c. As can be readily seen in Fig. 2a, the large nanoparticle tends to be nearly spherical in shape and incoherent with the matrix. In addition, we can also distinguish the inner core region with an appearance of lattice fringes from the outer shell region with a featureless appearance (presumably due to amorphization that will be discussed below), although the shell region does not appear to have a uniform thickness. On the other hand, ledges and facets can be readily seen at the oxide/matrix interfaces of these two small nanoparticles, which tend to be coherent or semi-coherent with the matrix. Detail analysis of the small nanoparticle in Fig. 2b is shown in Fig. 3. Here the orientation relationship between the nanoparticle and matrix can be derived from the fast Fourier transformation (FFT) image: $(0 \overline{1} 1)_{\alpha} \|(004)_{\mathrm{YAM}}$ and $[011]_{\alpha} \|[100]_{\mathrm{YAM}}$. A large coherent strain, $\Delta \epsilon=\frac{\left(d_{004}\right)_{Y A M}}{\left(d_{0 \overline{1} 1}\right)_{\alpha}}-1=30 \%$, can be generated if the oxide/matrix interface is fully coherent. However, the coherency strain can be reduced by inserting misfit dislocations at the interface to form semi-coherent interface.

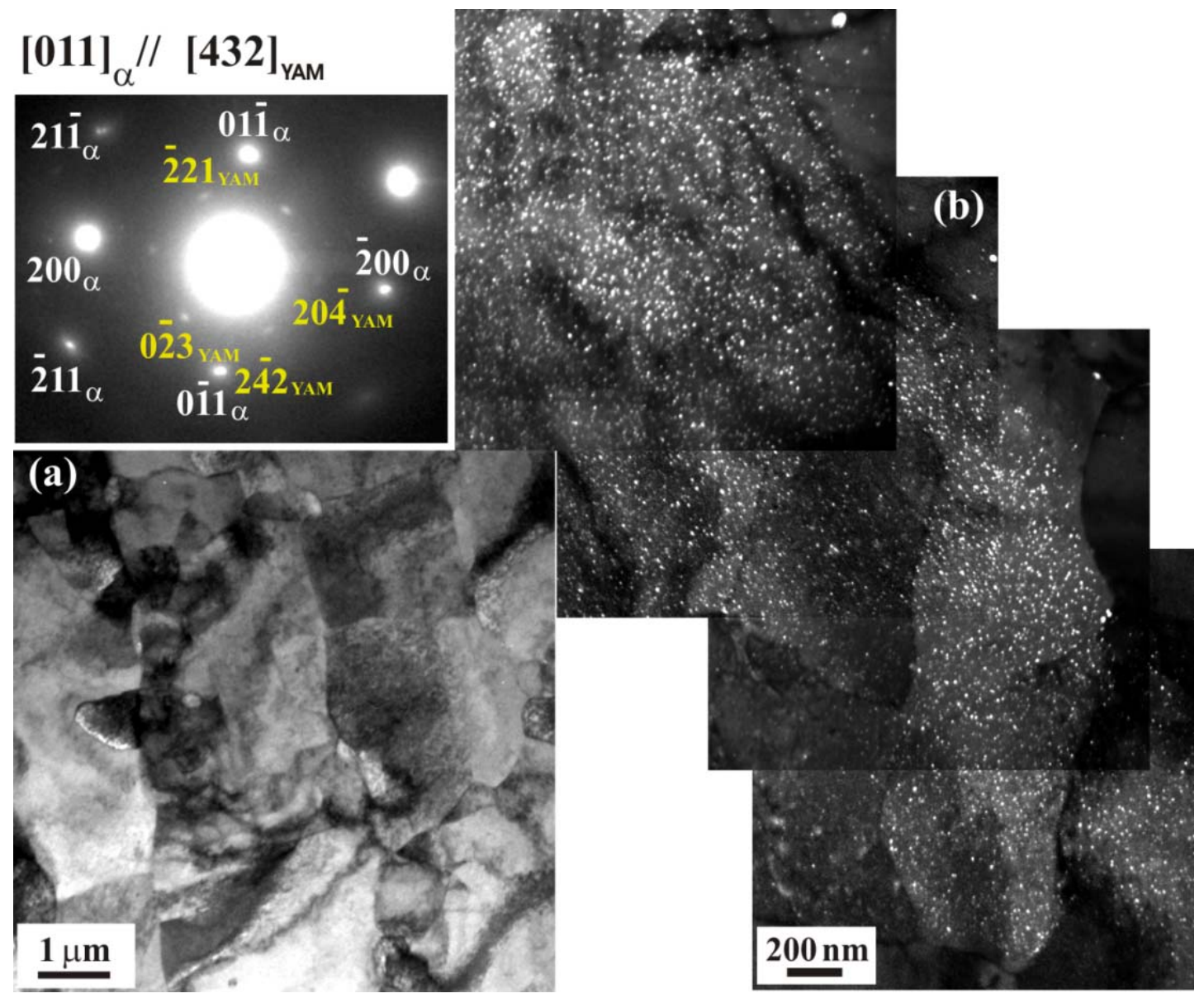


Simulation

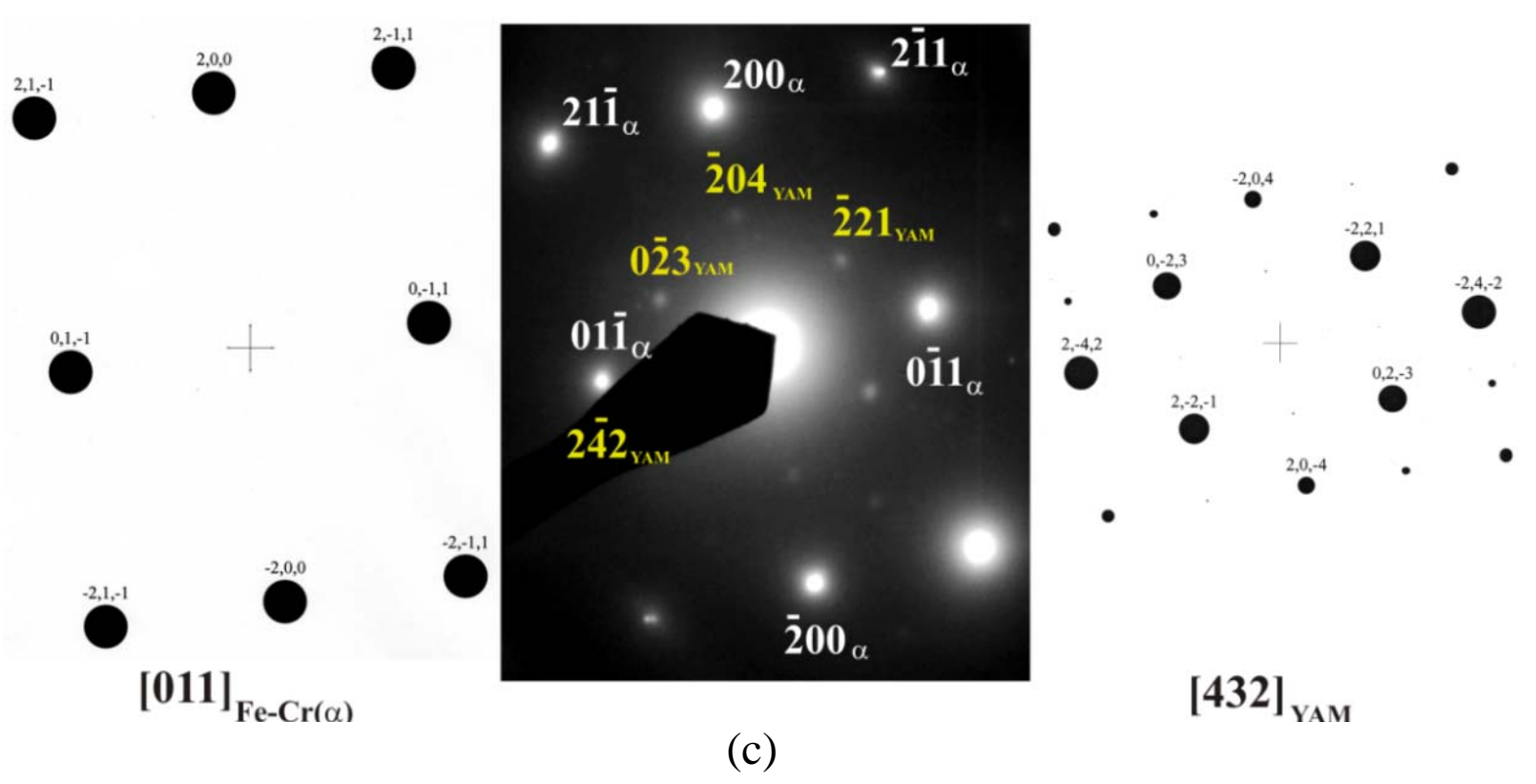

Fig. 1. (a) Bright-field TEM image shows typical grain morphology of K3-ODS steel, (b) dark-field TEM image and selected-area diffraction pattern of the [011 $]_{\mathrm{Fe}-\mathrm{Cr}(\alpha)} \|[432]_{\mathrm{YAM}-\mathrm{Zone}}$ show the formation of dense $\mathrm{Y}_{4} \mathrm{Al}_{2} \mathrm{O}_{9}$ nanoparticles in K3-ODS steel, (c) Observed and simulated diffraction patterns of $[011]_{\mathrm{Fe}-\mathrm{Cr}(\alpha)}$-zone and [432 $]_{\mathrm{YAM}}$-Zone for identifying the formation of $\mathrm{Y}_{4} \mathrm{Al}_{2} \mathrm{O}_{9}$ complex-oxide nanoparticles.
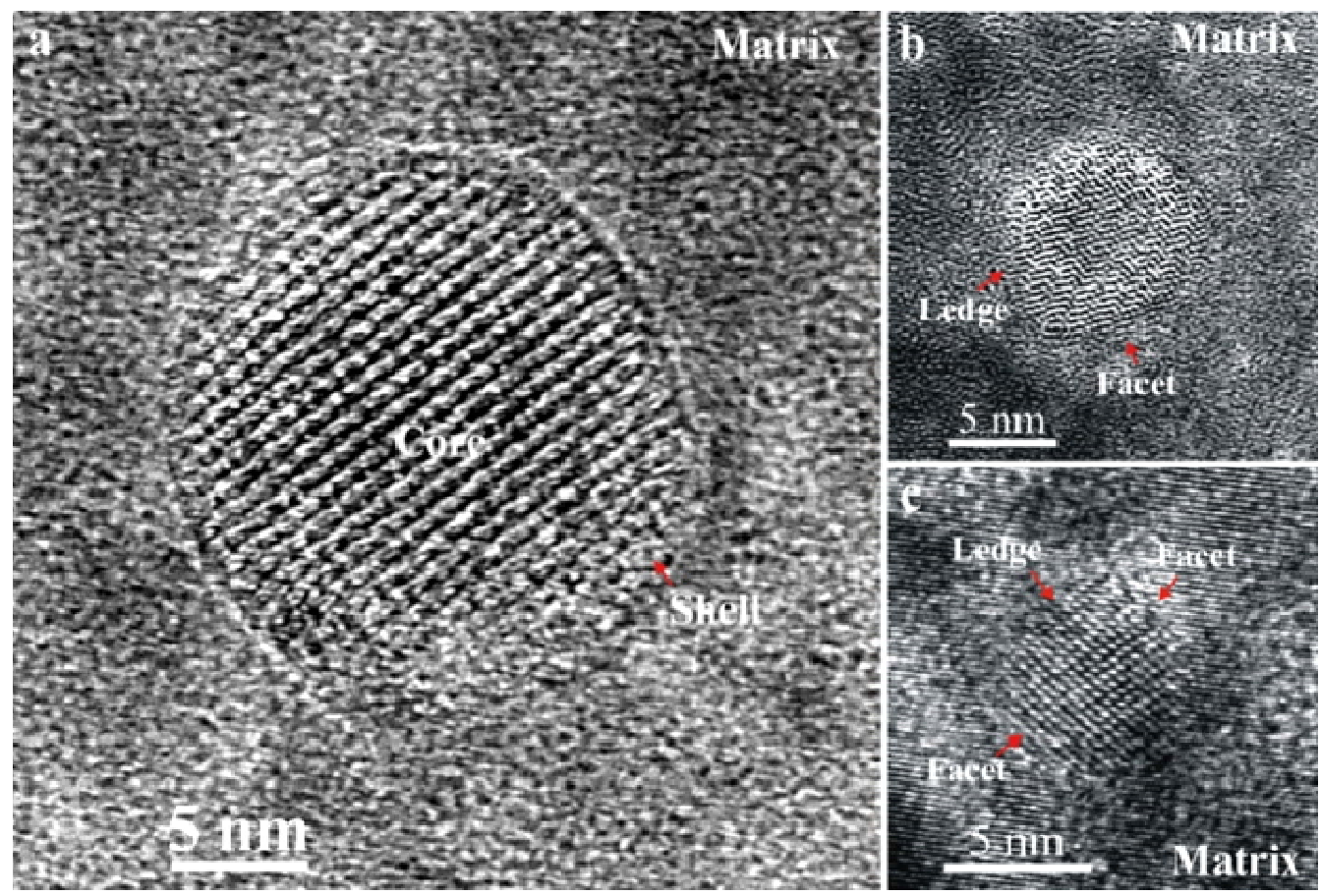

Fig. 2. HRTEM images of (a) a large nanoparticle (> $20 \mathrm{~nm})$ : incoherent interface associated with a core/shell structure and (b, c) small nanoparticles $(<10 \mathrm{~nm})$ : semi-coherent interfaces associated with facets and ledges. 


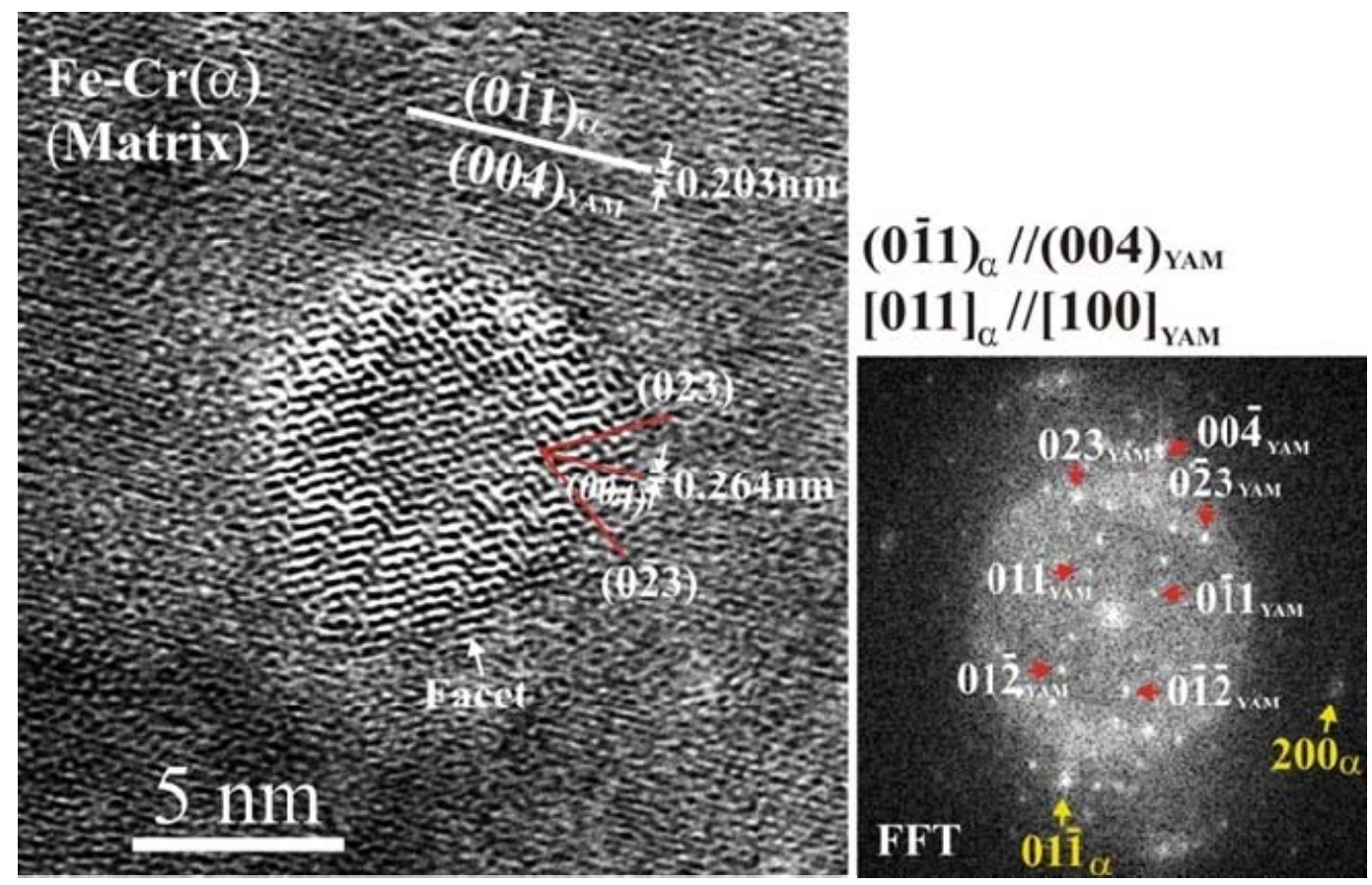

Fig. 3. HRTEM image shows a faceted interface between the small nanoparticle and the matrix. Orientation relationship between the oxide particle and the matrix can be derived from the FFT image.

The analysis of interfacial structure of the nanoparticle in Fig. 2c is shown in Fig. 4. In addition to facets and ledges, interface dislocations and small featureless domains can be readily seen at the oxide/matrix interface. Here a relatively smaller coherent strain, $\Delta \epsilon=\frac{\left(d_{\overline{115}}\right)_{Y A M}}{\left(d_{0 \overline{1} 1}\right)_{\alpha}}-1=7 \%$, is generated if the interface is fully coherent. Orientation relationship between the oxide nanoparticle and matrix, which is different from that in Fig. 3, can be derived from the fast Fourier transformation (FFT) image: $(0 \overline{1} 1)_{\alpha} \|(11 \overline{5})_{\text {YAM }}$ and $[011]_{\alpha} \|[732]_{\text {YAM. }}$. Figure 5 sheds light on why featureless domains formed in the shells of nanoparticles shown in Figs. 2a and 4. Here nucleation of a crystalline $\mathrm{Y}_{4} \mathrm{Al}_{2} \mathrm{O}_{9}$ domain (about $2 \mathrm{~nm}$ x $5 \mathrm{~nm}$ in size) can be readily seen within a partially crystallized oxide particle. In addition, several arrays of atoms can be found to align parallel to the $(0 \overline{2} 3)_{\text {YAM }}$ plane within the amorphous domain. An interfacial structure similar to that shown in Fig. 4 can be found at the interface between the crystalline $\mathrm{Y}_{4} \mathrm{Al}_{2} \mathrm{O}_{9}$ domain and matrix. Orientation relationship between the crystalline $\mathrm{Y}_{4} \mathrm{Al}_{2} \mathrm{O}_{9}$ domain and the matrix derived from the FFT image is $(0 \overline{1} 1)_{\alpha} \|(2 \overline{4} 2)_{\text {YAM }}$ and $[011]_{\alpha} \|[432]_{\text {YAM. Figure }}$ 6 shows another feature that can only be explained by the crystallization of amorphous oxide particle. Here two crystalline $\mathrm{Y}_{4} \mathrm{Al}_{2} \mathrm{O}_{9}$ domains, designated as the [432] $]_{\mathrm{I}}$ domain and the [221] $]_{\mathrm{II}}$ domain, were identified within a nanoparticle. The interfacial structure and orientation relationship between the [432] $\mathrm{I}$ domain and the matrix are the same to the oxide/matrix interface shown in Fig. 5. The interfacial structure and orientation relationship between the [221 $]_{\text {II }}$ domain and the matrix are shown in Fig. 7, in which facets, ledges, and amorphous remnant can again be found at the oxide/matrix interface. Additional orientation relationship is found between the oxide nanoparticle and matrix: $(0 \overline{1} 1)_{\alpha} \|$ $(2 \overline{3} 2)_{\text {YAM }}$ and $[011]_{\alpha} \|[221]_{\text {YAM. }}$. Here an even smaller coherent strain, $\Delta \epsilon=\frac{\left(d_{2 \overline{3} 2}\right)_{Y A M}}{\left(d_{0 \overline{1} 1}\right)_{\alpha}}-1=2 \%$, is measured. Thus, altogether four different orientation relationships have been identified between the oxide particle and the matrix. Clearly, the $\{011\}_{\alpha}$ planes act as habit planes for the nucleation of $\mathrm{Y}_{4} \mathrm{Al}_{2} \mathrm{O}_{9}$ nanoparticles according to these four different oxide-matrix orientation relationships. 


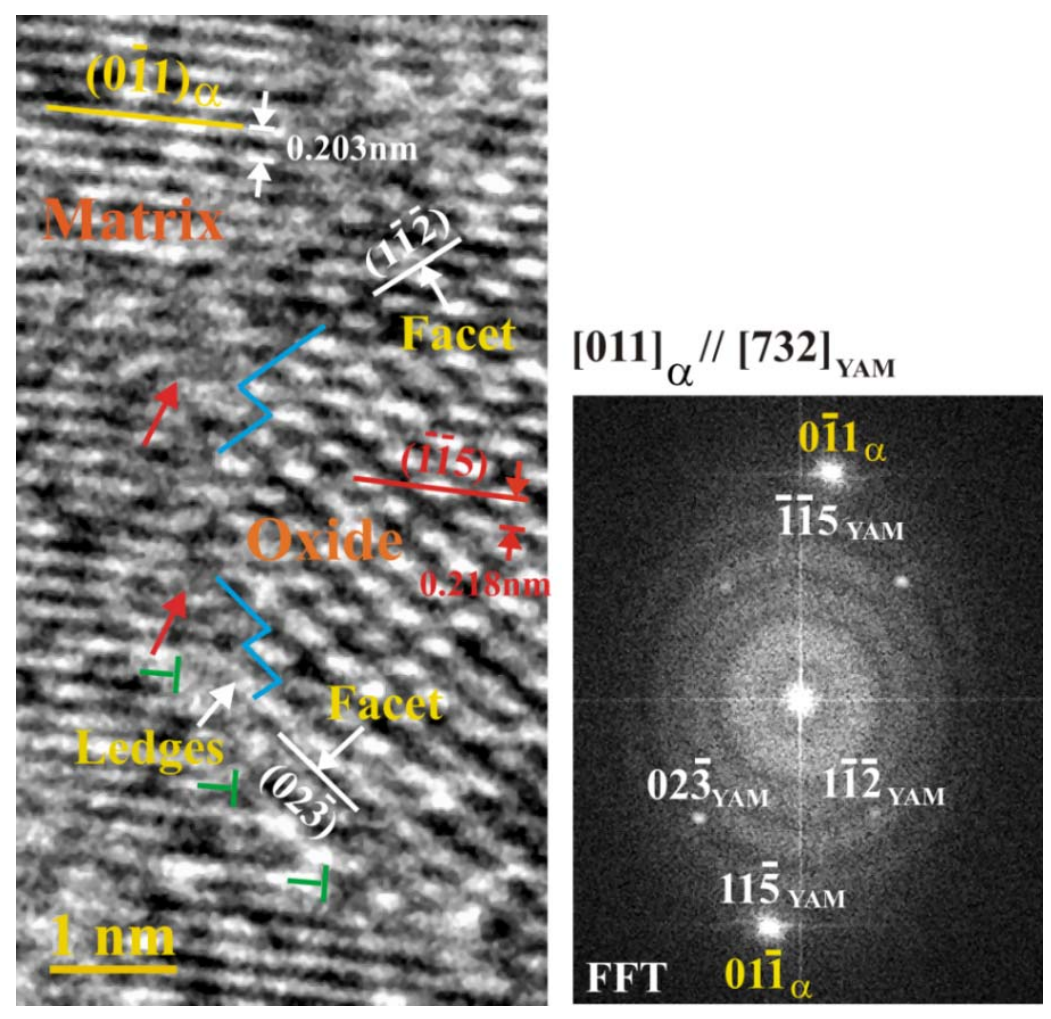

Fig. 4. HRTEM image shows the interfacial structure of the nanoparticle displayed in Fig. 2c; facets, ledges, dislocations, and thin shell of featureless domains (marked by red arrows) can be found at the interface. Orientation relationship between the oxide particle and the matrix can be derived from the FFT image.

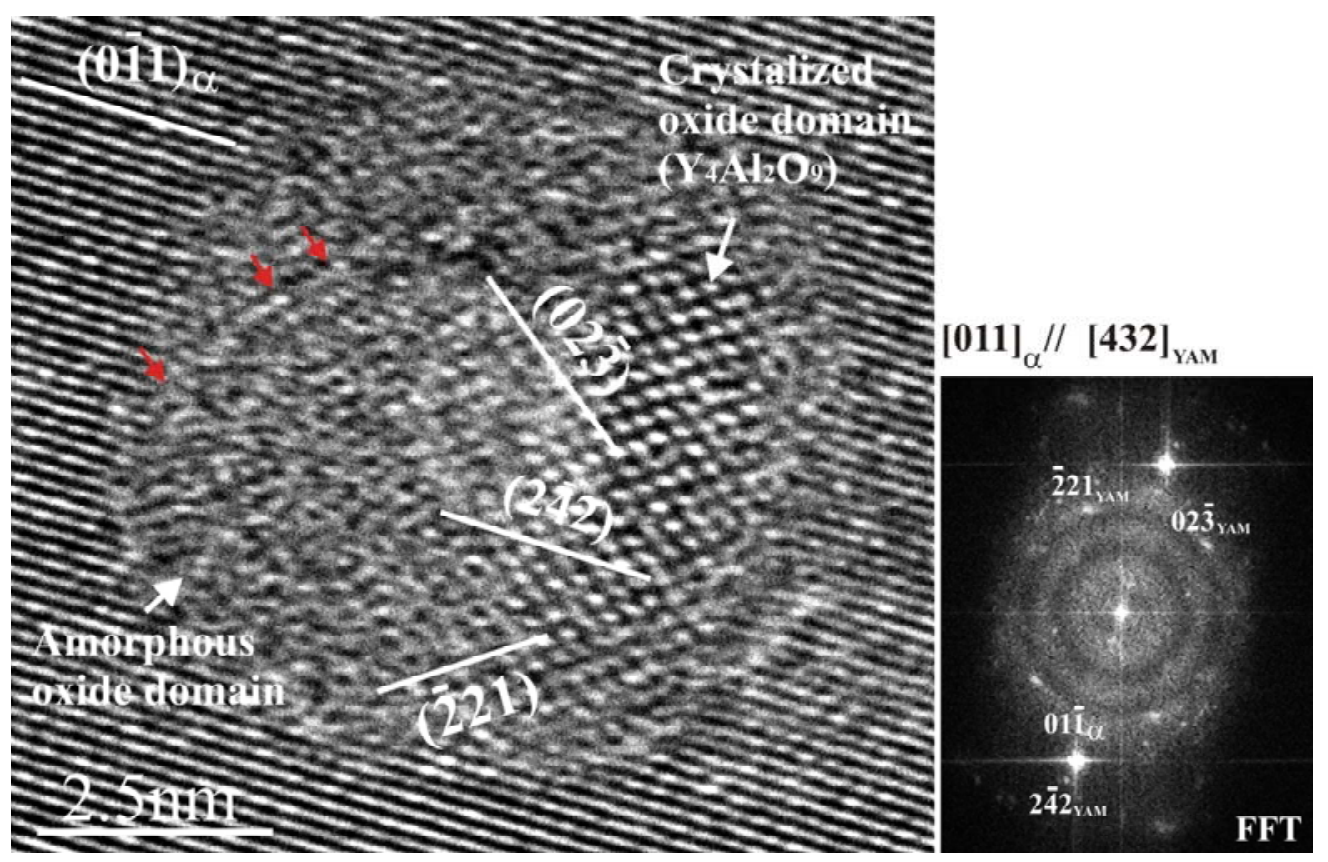

Fig. 5. HRTEM image shows a $\mathrm{Y}_{4} \mathrm{Al}_{2} \mathrm{O}_{9}$ crystal (2x5 nm) nucleated in an amorphous oxide particle; Several atomic arrays (marked by red arrows) can be found to align parallel to the $(0 \overline{2} 3)_{\text {Yam }}$ plane. Orientation relationship between the $\mathrm{Y}_{4} \mathrm{Al}_{2} \mathrm{O}_{9}$ crystal and the matrix can be derived from the FFT image. 


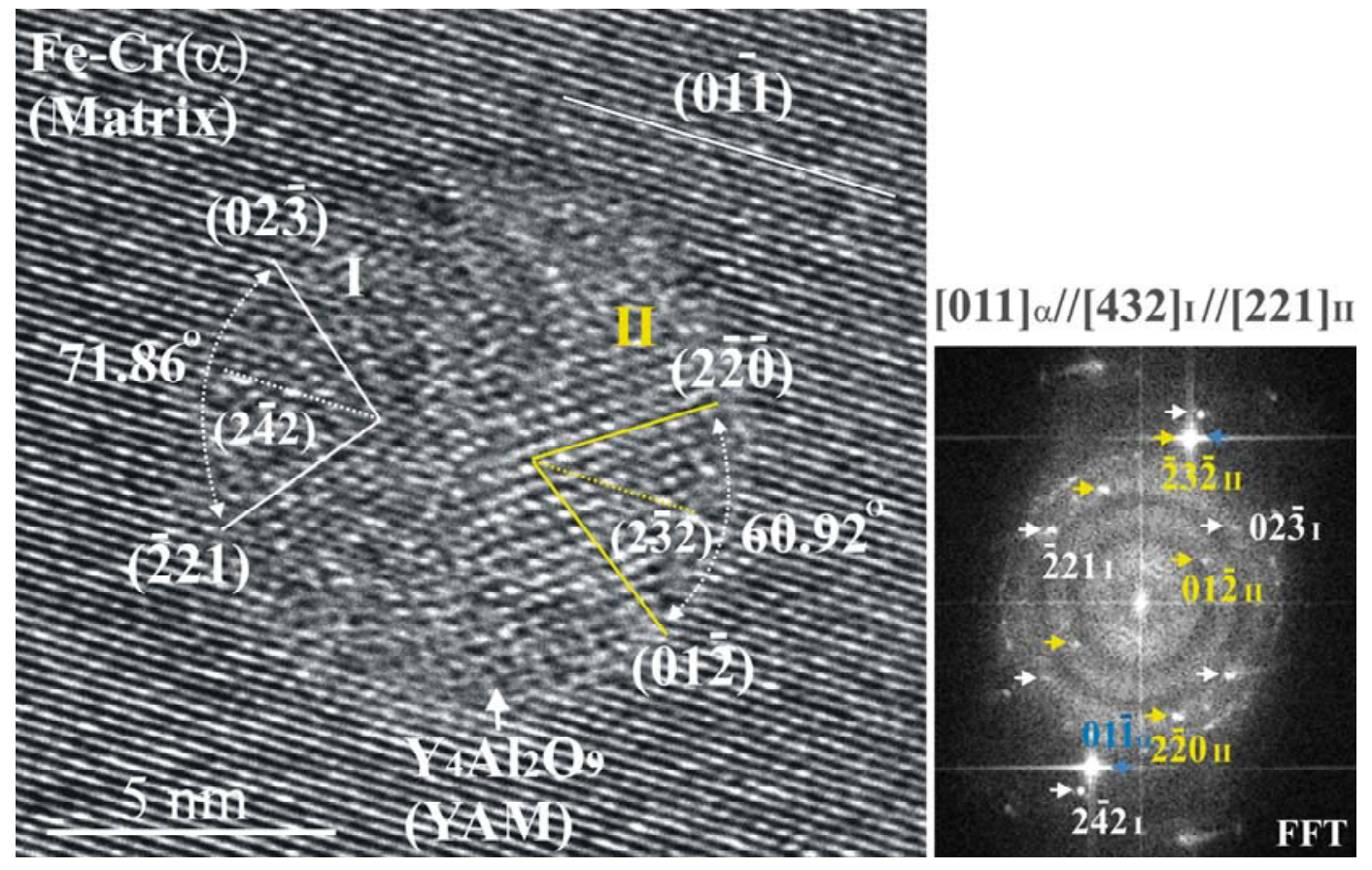

Fig. 6. HRTEM image shows the formation of multiple $\mathrm{Y}_{4} \mathrm{Al}_{2} \mathrm{O}_{9}$ domains within an oxide nanoparticle.

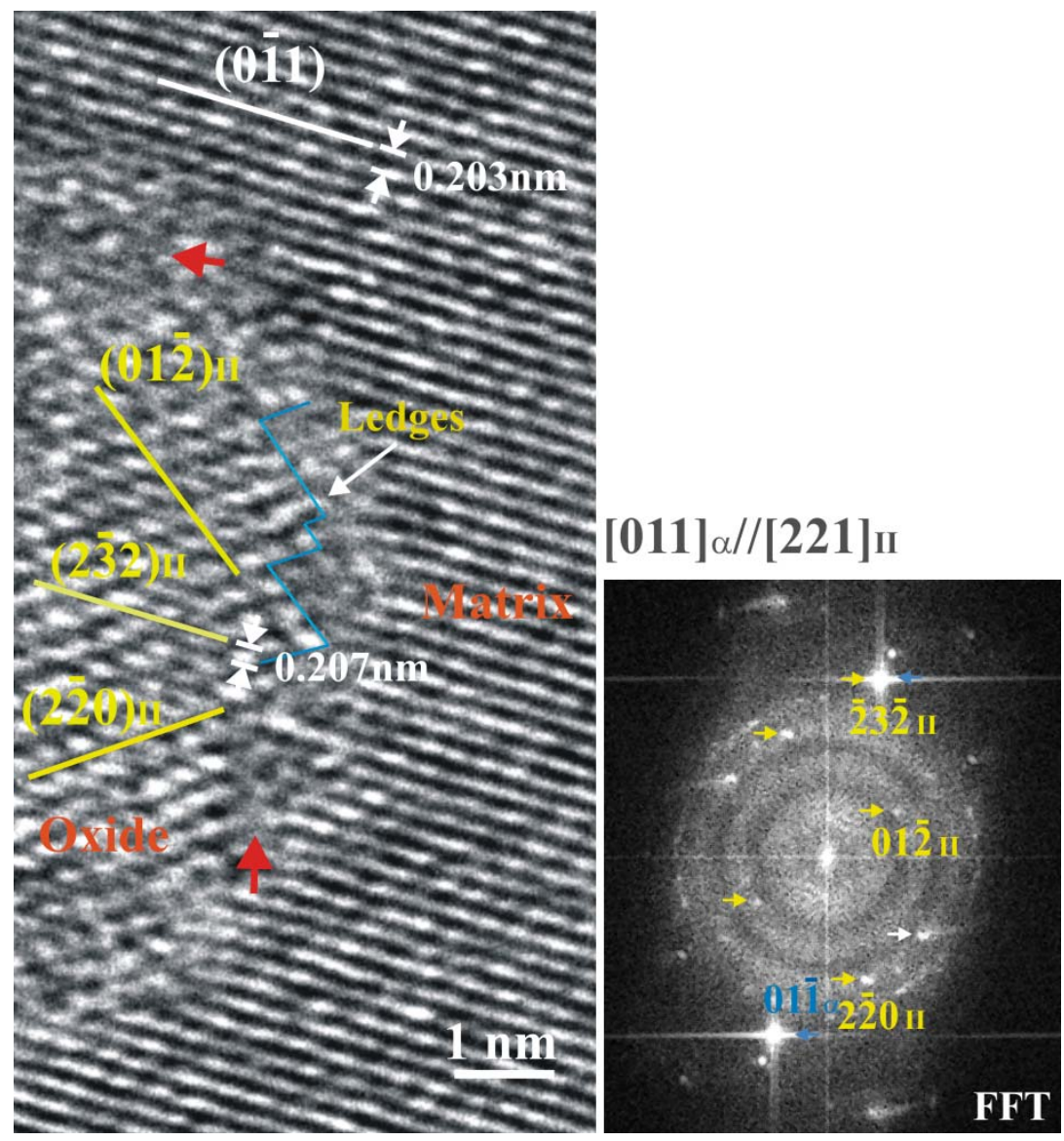

Fig. 7. HRTEM image shows the interfacial structure of the nanoparticle in Fig. 6. Facets, ledges, and amorphous remnant (marked by red arrows) can be found at the oxide (domain II)/matrix interface. 


\subsection{Proposed formation mechanisms of oxide nanoparticles}

Figure 8 shows the result of a K3-ODS steel sample annealed at $900{ }^{\circ} \mathrm{C}$ for 168 hours (one week). Here a perfectly spherical $\mathrm{Y}_{4} \mathrm{Al}_{2} \mathrm{O}_{9}$ nanoparticle without a core/shell structure can be seen as a result of the prolonged annealing. This result suggests that the core/shell structure of nanoparticles formed in the as-fabricated ODS steels are far from chemical equilibrium. Formation mechanisms of oxide nanoparticles are accordingly proposed and schematically illustrated in Fig. 9a based on the above HRTEM observations. The formation mechanism basically include the following three stages: (1) Fragmentation of starting $\mathrm{Y}_{2} \mathrm{O}_{3}$ particles to form finely-dispersed (nano or sub-nano) fragments during ball milling; (2) Agglomeration and amorphization of fragments mixed with matrix material to form clusters and agglomerates (designated as [MYO], M: alloying elements) during ball milling; (3) Crystallization of the amorphous oxide agglomerates to form oxide nanoparticles with a complex-oxide core and solute-enriched $\left(\mathrm{M}^{\prime}\right)$ shell. The contents of the complex-oxide core and solute-enriched shell are dependent on the composition of different ODS steels. Y-Al complex-oxide $\left(\mathrm{Y}_{\mathrm{x}} \mathrm{Al}_{\mathrm{y}} \mathrm{O}_{\mathrm{z}}\right)$ core can form in Al-contained ODS steels, $\mathrm{Y}$-Ti complex-oxide $\left(\mathrm{Y}_{\mathrm{x}} \mathrm{Ti}_{\mathrm{y}} \mathrm{O}_{\mathrm{z}}\right)$ core can form in Ti-contained ODS steels with no addition of $\mathrm{Al}$, and $\mathrm{Y}_{2} \mathrm{O}_{3}$ core can form in ODS steels with no additions of $\mathrm{Al}$ and Ti. The solute-enriched shell can be perceived as a result of the depletion of the solutes that are not involved in the oxidation reactions that lead to the formation of the complex-oxide core. The shell thickness is dependent on the size of nanoparticles since the larger the particle the more matrix material will participate in the agglomeration and amorphization stage and thus more solutes will be depleted from the oxide core during the crystallization stage, as illustrated in Fig. 9b. A solute-enriched shell forms when solute depletion rate due to the core building is greater than solute diffusion rate from the oxide/matrix interface during the crystallization stage.

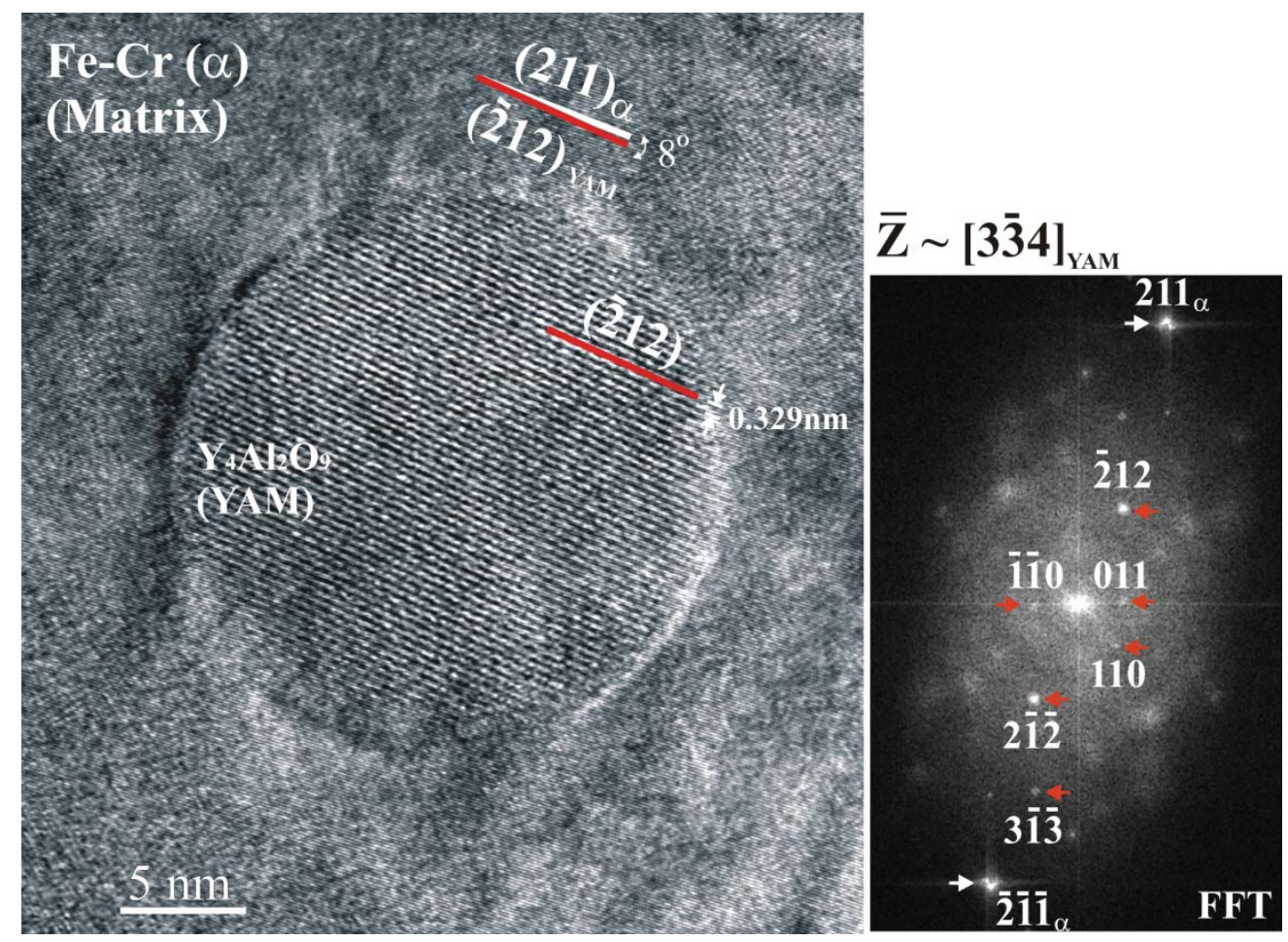

Fig. 8. HRTEM image shows that a large $\mathrm{Y}_{4} \mathrm{Al}_{2} \mathrm{O}_{9}$ nanoparticle $\left(>20 \mathrm{~nm}\right.$ ) of the $[3 \overline{3} 4]_{\mathrm{YAM}}$-zone was observed in an ODS steel sample after prolonged annealing at $900{ }^{\circ} \mathrm{C}$ for 168 hours. The nanoparticle becomes perfectly spherical without a core/shell structure. 
(a)

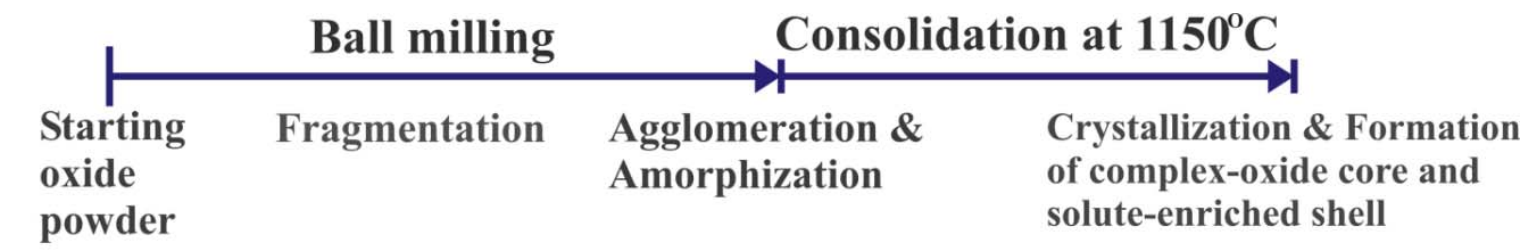
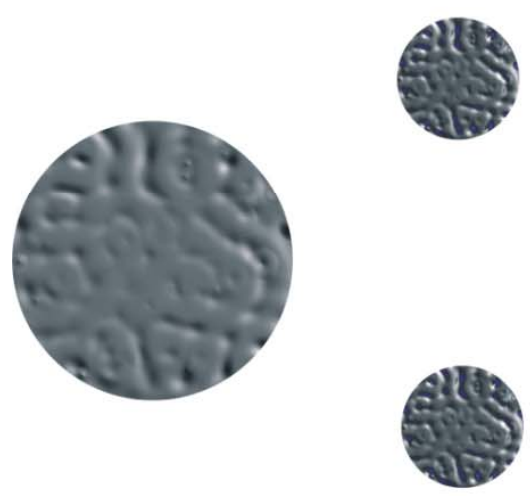

$\mathrm{Y}_{2} \mathrm{O}_{3}$

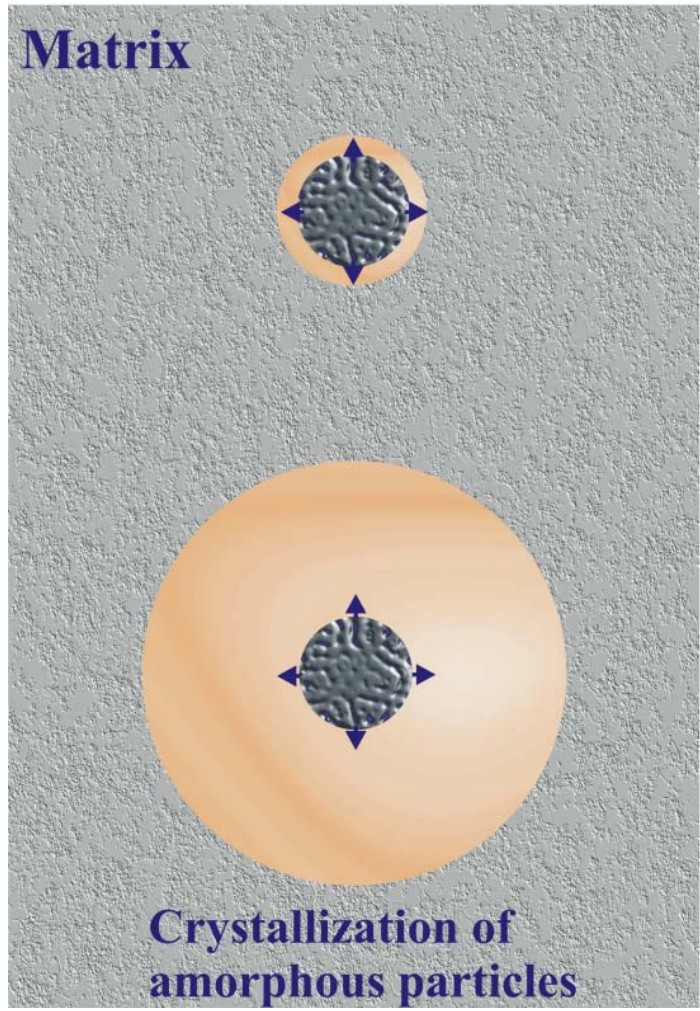

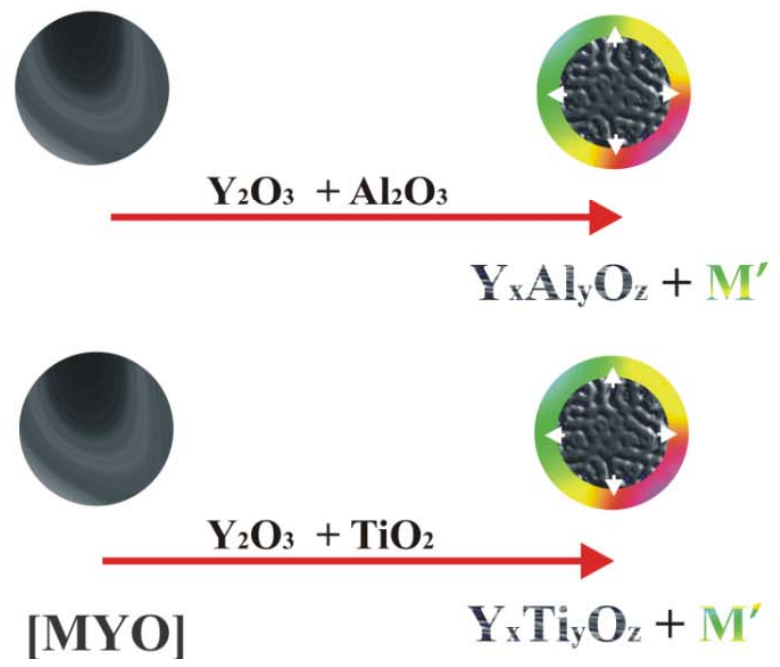

(b)

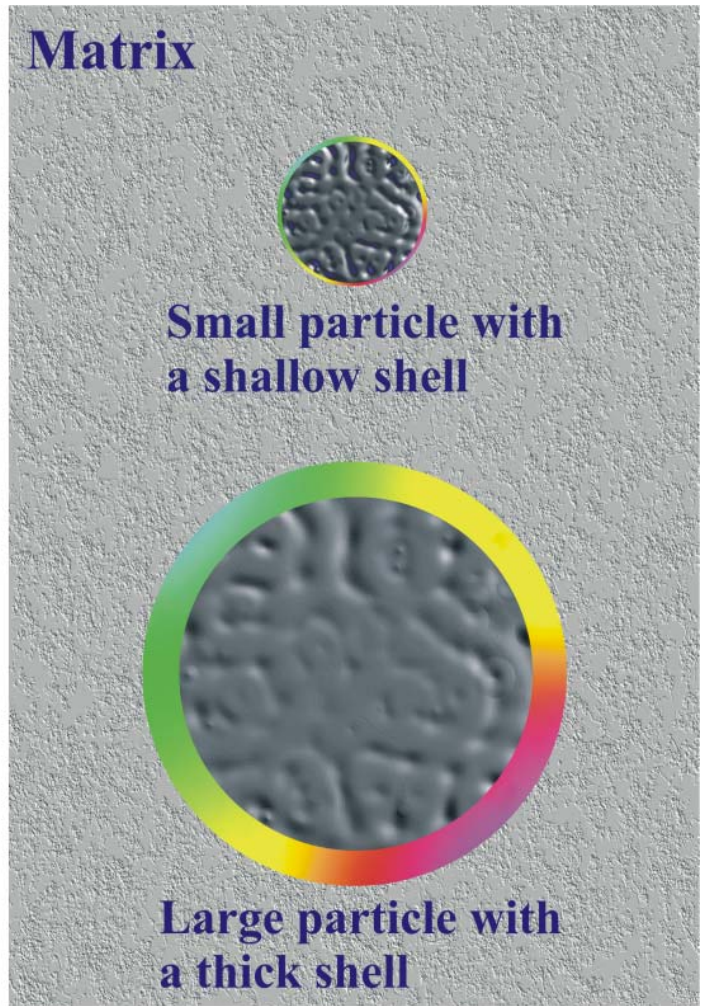

Fig. 9. Schematic illustrations show (a) a three-stage mechanism for the formation of oxide nanoparticles containing a core/shell structure during a mechanical alloying process and (b) size effect on the formation of core/shell structures in oxide nanoparticles; a solute-enriched shell forms when solute depletion rate from the core is greater than solute diffusion rate from the oxide/matrix interface during the crystallization stage. 


\subsection{Bubble formation in dual-beam irradiated K3-ODS steel}

According to the rate theory of swelling due to void growth in irradiated metals [21, 22, 23]: under steady-state conditions, the radial growth rate of helium-contained cavity is determined by both excess vacancy flux $(\mathrm{S})$ and helium gas pressure $\left(\mathrm{P}_{\mathrm{g}}\right)$ that in turn is determined by the content of helium atoms $\left(\mathrm{N}_{\mathrm{g}}\right)$ in each cavity. The increase in both $\mathrm{S}$ and $\mathrm{N}_{\mathrm{g}}$ in the high-energy neutron damage environment of fusion reactors can lead to the decrease in the critical radius of cavity $\left(r_{c}^{c *}\right)$ for rapid void growth and therefore gives rise to accelerated swelling. The motivation of current investigation is to clarify a crucial ODS concept (or hypothesis) for radiation tolerance. That is, the onset of swelling of ODS steels can be delayed by the formation of high-density helium-contained stable cavities in fine dispersion of oxide nanoparticles to dilute attainable helium atoms for each stable cavity to below a critical quantity $\left(N_{g}^{*}\right)$ for rapid void growth. As a result, a greater helium concentration can be accommodated in irradiated ODS steels. The existence of critical quantities, $r_{c}^{c *}$ and $N_{g}^{*}$, for bubble-void conversion leads to the expectation of a bimodal cavity size distribution. When some cavities have accumulated more than $N_{g}^{*}$ helium atoms, they will rapidly grow to larger sizes. Other cavities containing less than $N_{g}^{*}$ helium atoms remain behind at their stable radius. Thus, it is expected that rapid void growth will eventually begin when enough injected gas is accumulated, and a bimodal cavity size distribution should then be observed. The goal of the present work was to observe the helium bubbles and/or voids formed in the dual-beam irradiated K3-ODS steel. Observations of interfacial cavities (bubbles) and cavity size distribution are the major focus.

Since cavity formation is dependent not only on irradiation conditions (dose, He/dpa ratio) but also on micro-composition (solute effect) and micro-structure (dislocation structure, boundary structure, and local density of dispersoids) of irradiated material, precise interpretation of cavity development and distribution is not an easy task. However, the cavities (helium bubbles) formed in the irradiated ODS steel appear in a preliminary analysis to depend on the size and the local density of oxide nanoparticles. The effect of particle size on bubble formation is shown in Fig. 10. Here large nanoparticles (> $20 \mathrm{~nm}$, marked by red arrows) were observed in association with large coalesced bubbles, while small nanoparticles (<10 nm, marked by yellow arrows) were observed in association with small isolated bubbles. This indicates that large nanoparticles are detrimental since cavities (bubbles) associated with them grow more rapidly. Figure 11 shows a typical region where high-density small nanoparticles are well decorated with a "unimodal distribution” of small bubbles (about $1 \mathrm{~nm}$ to $2 \mathrm{~nm}$ in diameter) as a result of the helium-dilution effect. Notice that these small bubbles are mostly located at the oxide/matrix interfaces. Figure 12 on the other hand shows a typical low particle-density region where a "bimodal distribution" of isolated bubbles (about $3 \mathrm{~nm}$ to $5 \mathrm{~nm}$ in diameter) and coalesced bubbles (about $3 \mathrm{~nm}$ x $6 \mathrm{~nm}$ to $3 \mathrm{~nm} \times 12 \mathrm{~nm}$ in size) can be found in the matrix. Notice that one nanoparticle (about $10 \mathrm{~nm}$ in diameter) in the low particle-density region was observed to be associated with three isolated bubbles (about $3 \mathrm{~nm}$ to $4 \mathrm{~nm}$ in diameter) and a coalesced bubble (about $3 \mathrm{~nm} \times 9 \mathrm{~nm}$ in size). Further investigations are underway in order to better understand and describe the cavity formation kinetics that is operating in dual-beam irradiated ODS steels. 

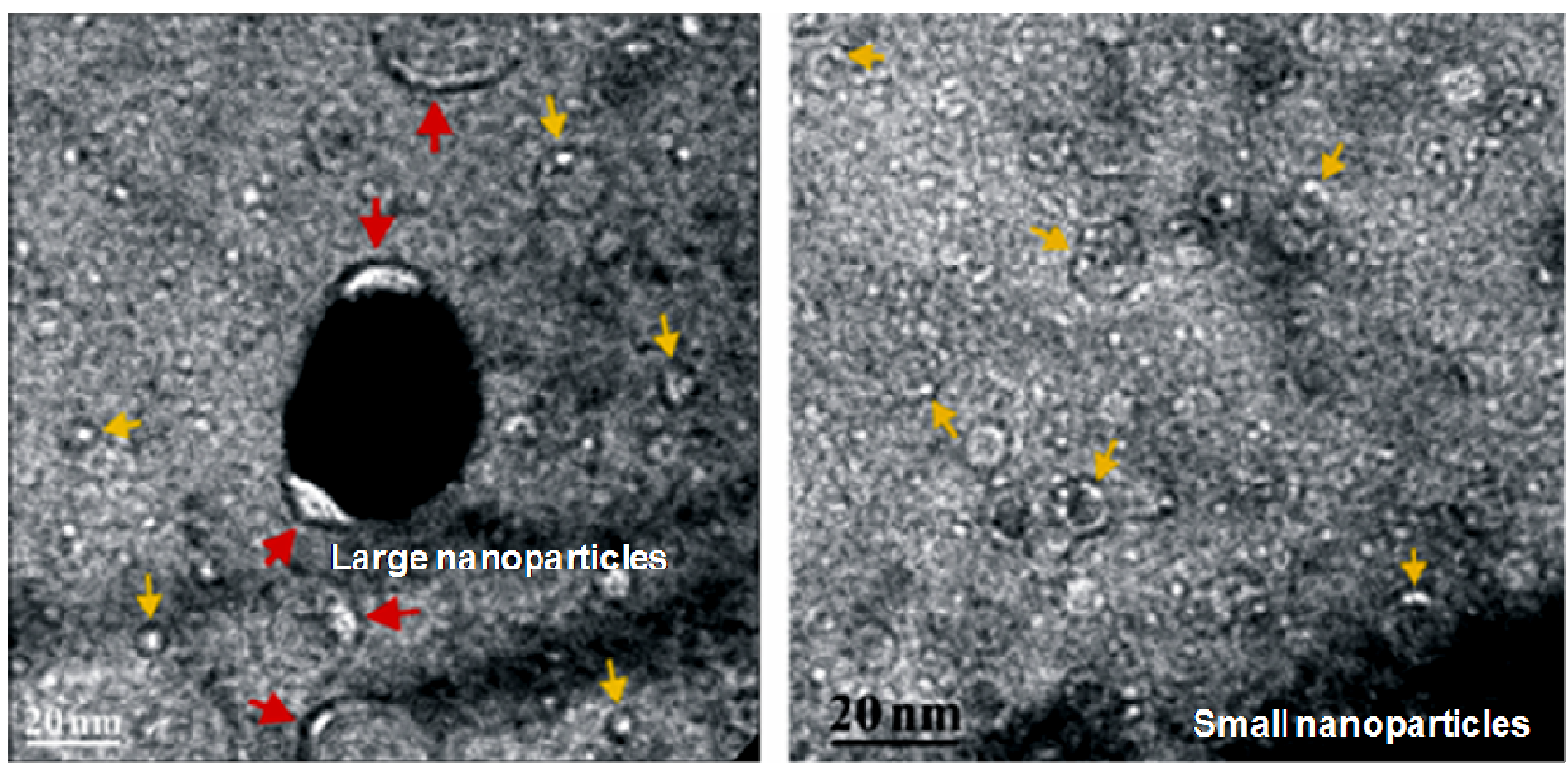

Fig. 10. TEM images show the effect of nanoparticle size on cavity (bubble) formation in irradiated K3ODS steel. Large nanoparticles (> $20 \mathrm{~nm})$ are marked by red arrows; small nanoparticles $(<10 \mathrm{~nm})$ are marked by yellow arrows. The images were taken with an under-focus condition: $-200 \mathrm{~nm}$.

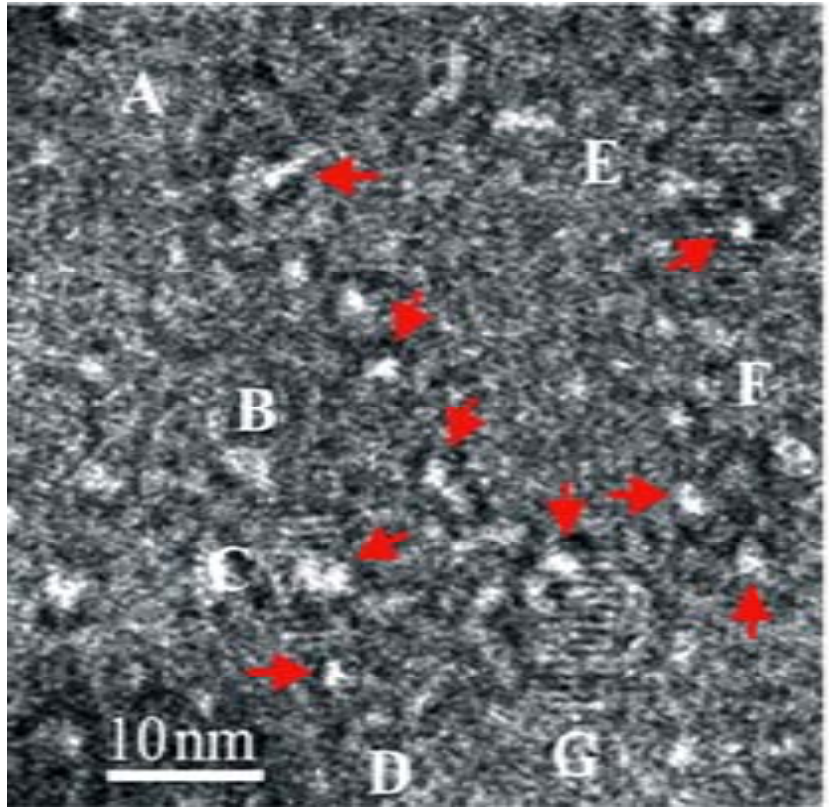

Underfocus $(-1 \mu \mathrm{m})$

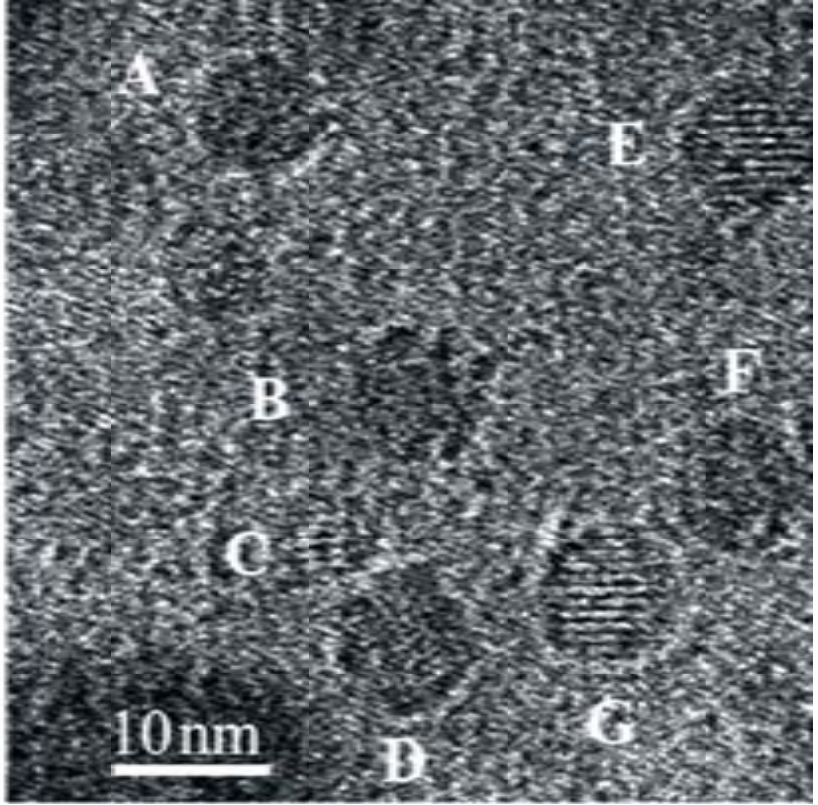

Overfocus $(+0.5 \mu \mathrm{m})$

Fig. 11. TEM images taken from the same area under different focus conditions show the "unimodal distribution" of helium bubbles in a high particle-density region; helium bubbles are mostly located at the oxide/matrix interfaces (some are marked by red arrows). 


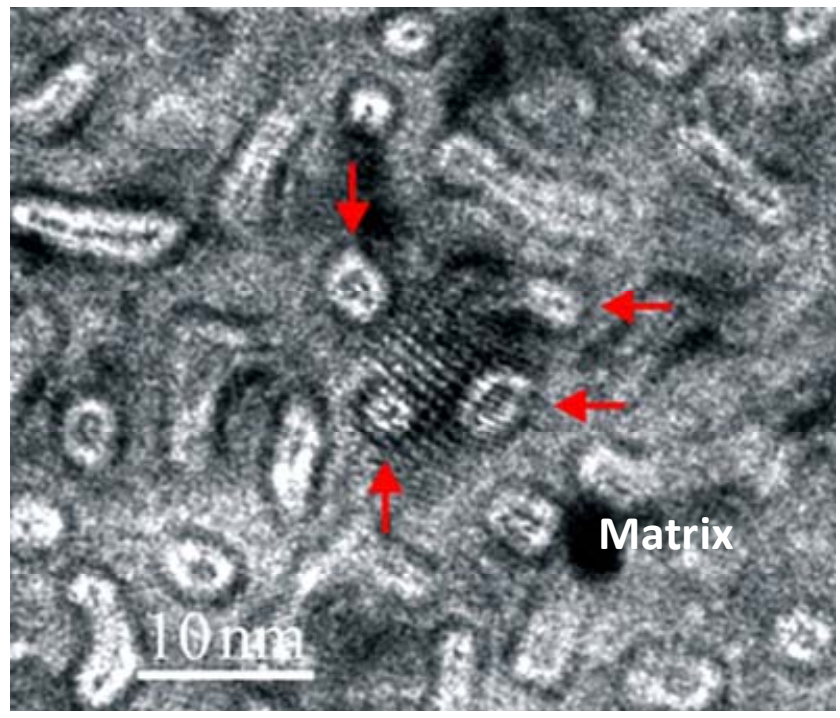

Underfocus $(-0.5 \mu \mathrm{m})$

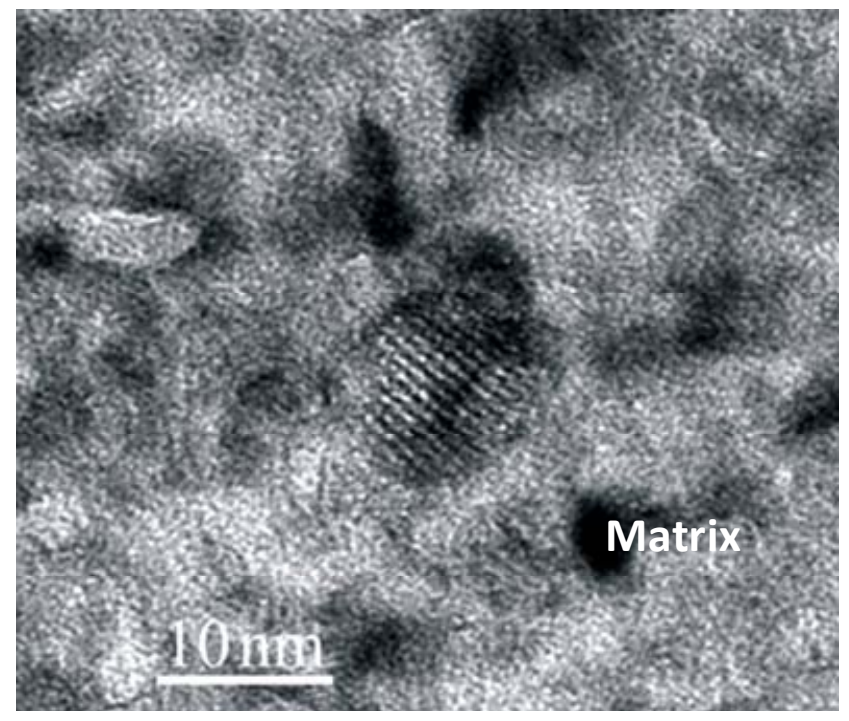

In-focus

Fig. 12. TEM images taken from the same area under different focus conditions show the "bimodal distribution” of helium bubbles in a low particle-density region; four bubbles (marked by red arrows) were observed in association with an oxide nanoparticle; the elongated cavities in the matrix are likely formed due to the coalescence of small bubbles.

\section{Conclusion}

The crystal and interfacial structures of nanoparticles in a 16Cr-4Al-2W (K3) ODS steel have been investigated using HRTEM imaging techniques. Crystal structure of the nanoparticles is identified to be mainly monoclinic $\mathrm{Y}_{4} \mathrm{Al}_{2} \mathrm{O}_{9}(\mathrm{YAM})$ oxide compound. Large nanoparticles ( $>20 \mathrm{~nm}$ ) usually have a spherical shape and tend to be incoherent with the matrix; small nanoparticles ( $<10 \mathrm{~nm})$, usually exhibiting facets and ledges at the oxide/matrix interfaces, tend to be coherent or semi-coherent with the matrix. A structure of $\mathrm{Y}_{4} \mathrm{Al}_{2} \mathrm{O}_{9}$ oxide core associated with amorphous shell is found to form in both large and small nanoparticles in as-fabricated ODS steel. The core/shell structure disappears after prolonged annealing at $900{ }^{\circ} \mathrm{C}$ for 168 hours, which suggests that the core/shell structures formed as a result of the crystallization of amorphous oxide agglomerates are far from chemical equilibrium. A three-stage formation mechanism of ODS nanoparticles is accordingly proposed to rationalize the formation of core/shell structures. Preliminary TEM results show that the formation of cavities (helium bubbles) in the dual-beam irradiated K3-ODS steel is dependent on both the size and the density of the oxide nanoparticles. The large nanoparticles (> $20 \mathrm{~nm}$ ) are detrimental since cavities (bubbles) associated with large particles grow more rapidly.

\section{Acknowledgements}

This work was performed under the auspices of the U.S. Department of Energy by Lawrence Livermore National Laboratory under Contract DE-AC52-07NA27344. Work at LLNL was funded by the Laboratory Directed Research and Development Program at LLNL under project tracking code 09SI-003. The authors gratefully acknowledge R. Krueger for the design of sample holder for the 
irradiation experiment, S. Miro and J.-P. Gallien for beam management, H. Martin for his technical support for the irradiation experiment, and N. Teslich and R. Gross for their works on TEM sample preparations.

\section{Reference}

1. K. Ehrlich, Phil. Trans. R. Soc. Lond. A 357 (1999) 595.

2. EE. Bloom, S. J. Zinkle, F.W. Wiffen, J. Nucl. Mater. 329-333 (2004) 12.

3. S. Ukai, M. Fujiwara, J. Nucl. Mater. 307-311 (2002) 749.

4. E.E. Bloom, J.T. Busby, C.E. Duty, P.J. Maziasz, T.E. McGreevy, B.E. Nelson, B.A. Pint, P. F. Tortorelli, S.J. Zinkle, J. Nucl. Mater. 367-370 (2007) 1.

5. J. Boutard, A. Alamo, R. Lindau, M. Rieth, C. R. Physique 9 (2008) 287.

6. I.-S Kim, J.D. Hunn, N. Hashimoto, D.L. Larson, P.J. Maziasz, K. Miyahara, E.H. Lee, J. Nucl. Mater. 280 (2000) 264.

7. K. Yutani, H. Kishimoto, R. Kasada, A. Kimura, J. Nucl. Mater. 367-370 (2007) 423.

8. S. Uki, T. Nishida, H. Okada, T. Okuda, M. Fujiwara, K. Asabe, J. Nucl. Sci. Technol. 34 (3) (1997) 256.

9. S. Uki, T. Nishida, T. Okuda, T. Yoshitake, J. Nucl. Sci. Technol. 35 (4) (1998) 294.

10. Y. Serruys, P. Trocellier, S. Miro, J. Nucl. Mater. 386 (2009) 967.

11. Y. Serruys, M.O. Ruault, P. Trocellier, Comptes Rendus Physique 9 (2008) 437.

12. A. Nørlund Christensen and R.G. Hazell, Acta Chemica Scandinavica 45 (1991) 226.

13. W.Y. Ching, Y.N. Xu, Physical Review B 59 (20) (1999) 12815.

14. R. Kasada, N. Toda, K. Yutani, H.S. Cho, H. Kishimoto, A. Kimura, J. Nucl. Mater. 367-370 (2007) 222.

15. V. de Castro, T. Leguey, M.A. Monge, A. Munoz, R. Pareja, D.R. Amador, J.M. Torralba, M.

Victoria, J. Nucl. Mater. 322 (2003) 228.

16. T. Okuda, M. Fujiwara, J. Mater. Sci. Lett. 14 (1995) 1600.

17. Y. Kimura, S. Takaki, S. Suejima, R. Uemori, H. Tamehiro, ISIJ International, 39 (2) (1999) 176.

18. H. Sakasegawa, M. Tamura, S. Ohtsuka, S. Ukai, H. Tanigawa, A. Kohyama, M. Fujiwara, J. Alloys \& Compounds 452 (2008) 2.

19. E. A. Marquis, Appl. Phys. Lett. 93 (2008) 181904.

20. M. Klimiankou, R. Lindau, A. Möslang, J. Nucl. Mater. 386-388 (2009) 553.

21. L.K. Mansur, W.A. Coghlan, J. Nucl. Mater. 119 (1983) 1.

22. L.K. Mansur, E.H. Lee, P.J. Maziasz, A.P. Rowcliffe, J. of Nucl. Mater., 141-143 (1986) 633. 